\title{
Successful non-surgical management of pleuroparenchymal fistula following cervical intraspinal empyema
}

\author{
Christopher UII1, Mirko Aach2, Josef Reichert³, Thomas Armin Schildhauer1, Justyna Swol4 \\ 1 Department of General and Trauma Surgery, BG University Hospital Bergmannsheil, Bochum \\ 2 Department of Spinal Cord Injuries, BG University Hospital Bergmannsheil, Bochum \\ 3 Department of Cardiothoracic Surgery, BG University Hospital Bergmannsheil, Bochum \\ 4 Department of Pulmonology, Intensive Care Medicine, Paracelsus Medical University, Nuremberg, \\ Germany
}

\begin{abstract}
Pulmonary infections are life-threatening complications in patients with spinal cord injuries. In particular, paraplegic patients are at risk if they are ventilator-dependent. This case history refers to a spinal cord injury with a complete sensorimotor tetraplegia below $\mathrm{C} 2$ caused by a septic scattering of an intraspinal empyema at C2-C5 and T3-T4. A right-sided purulent pneumonia led to a complex lung infection with the formation of a pleuroparenchymal fistula. The manuscript describes successful, considerate, non-surgical management with shortterm separate lung ventilation. Treatment aimed to achieve the best possible result without additional harm.

A variety of surgical and conservative strategies for the treatment of pleuroparenchymal fistula (PPF) have been described with different degrees of success. We detail the non-surgical manage-
\end{abstract}

Corresponding author: Justyna Swol, Department of Pulmonology, Intensive Care Medicine, Paracelsus Medical University, Nuremberg, Germany, Prof. Ernst-Nathan-Str. 1, 90419 Nuernberg, Germany.

Tel. +49.931.20131410. E-mail: jswol@icloud.de

Key words: Spinal abscesses; paraplegia; pleuroparenchymal fistula; talc pleurodesis; double-lumen tube ventilation.

Contributions: CU, patient treatment, manuscript design and writing; MA, JR, TAS, contribution patient treatment, manuscript revision; JS patient treatment, manuscript writing and revision.

Conflict of interest: The authors have reported no conflicts of interest with any companies/organizations whose products or services may be discussed in this article.

Received for publication: 8 October 2017

Accepted for publication: 10 December 2017

CCopyright C. Ull et al., 2018

Tipografia PI-ME Editrice, Italy

Monaldi Archives for Chest Disease 2018; 88:889

doi: 10.4081/monaldi.2018.889

This article is distributed under the terms of the Creative Commons Attribution Noncommercial License (by-nc 4.0) which permits any noncommercial use, distribution, and reproduction in any medium, provided the original author(s) and source are credited. ment of a persistent PPF with temporary separate lung ventilation (SLV) via a double-lumen tube (DLT) in combination with talc pleurodesis as an approach in patients who are unable to undergo surgical treatment.

\section{Introduction}

Pulmonary infections are common and life-threatening complications in patients with spinal cord injuries. In particular, paraplegic patients are at a higher risk if they are dependent on ventilation. Broncho- or pleuroparenchymal fistula is a rare and challenging condition. Persistent leakage causes a chronic infection and prolongs the stay in the intensive care unit. Ventilator settings can be difficult to obtain, and weaning can be even more difficult than usual and may even be impossible. Additionally, chronic infection reduces the energy and motivation of the patient and makes further rehabilitation more difficult.

Pulmonary surgical procedures remain the leading cause of fistulas in the bronchoparenchymal tree [1]. A broncho- or pleuroparenchymal fistula (PPF) is a communication between the pleural space and the lung parenchyma and is associated with significant morbidity and mortality [2-5]. The incidence of this condition ranges from $0.93 \%$ to $20 \%$ after pneumonectomy and $<1 \%$ after lobectomy [2,3,6]. A variety of surgical and conservative strategies for the treatment of PPF have been described with varying degrees of success. Pleurodesis is one of the non-surgical treatment possibilities. Sterile talc is inexpensive and is the most effective chemical agent for pleurodesis, but its application can lead to dyspnea and respiratory failure.

\section{Case Reports}

A 62-year-old male presented initial symptoms of fever and pneumonia. On the day of admission, the patient experienced a force reduction in his left hand, which rapidly spread to left-sided hemiparesis with dysarthria and dysphagia. Computer tomography of the brain and cervical spine, performed in the referring hospital, showed an ischemic infarction in the cerebellar region, the medulla oblongata, and the cervical myelon, as well as a pronounced retropharyngeal abscess and an intraspinal empyema at C2-C5 and T3-T4. The intraspinal abscesses were treated with a hemilaminectomy and a discectomy at C5-C6 with cage implantation. A pleural decortication and an atypical partial pneumonectomy were also performed due to a right-sided pyothorax with emphysematous lung tissue.

The patient suffered from spinal cord injury with a complete sensorimotor tetraplegia below $\mathrm{C} 2$ caused by a septic scattering of spinal ab- 
scesses at $\mathrm{C} 2-\mathrm{C} 5$ and T3-T4. An examination revealed a flaccid tetraplegia; musculoskeletal reflexes were not present, and Babinski reflexes, with the toe-spreading phenomenon, were more dominant on the right than the left. No sphincter tonus was present.

An air leak was present in this ventilated patient after prolonged treatment with an enclosed chest tube for more than 6 weeks. No bronchoscopic images were available to identify the fistula in the bronchial tree, but it was asked whether there could be an adequate parenchymal closure of the fistula.

The patient was against surgical treatment due to his general condition and the current prolonged course of treatment. During bilateral mechanical ventilation, the talc pleurodesis via chest tube failed twice because the patient became hypoxic when the chest tube was disconnected. An isolated ventilation of the left lung with a single-lumen tube was attempted instead. However, this procedure repeatedly failed because the cuff became leaky and could not seal the left main bronchus. At that time, it was not possible to use a modified single-lumen tube for separate lung ventilation (SLV), as described in the literature $[7,8]$. Extracorporeal membrane oxygenation (ECM0) for lung support was also considered for this patient. Veno-venous ECMO for patients with lung failure has been performed in this ICU since 2008, but clinicians were concerned about the use of ECMO as a rescue option in this case [9]. The use of ECMO to treat PPF has shown promising results in case reports because it can provide a therapeutic bridge to lung-protective ventilation and the remainder of the lung and allows for PPF closure [10-13].

Ultimately, we decided to ventilate the lungs separately through a double-lumen tube (DLT). The procedure using double lumen ventilation was the fourth attempt at pleurodesis. Talc pleurodesis was performed as follows: the patient was placed in a supine position in the bed and was preoxygenated with a flow of $1.0 \mathrm{FiO}_{2}$. Intravenous propofol $(300 \mathrm{mg} / \mathrm{h})$ and sufentanil $(50 \mu / \mathrm{h})$ were used for sedation; $100 \mathrm{mg}$ of intravenous rocuronium was used for muscle relaxation. A DLT was used for orotracheal intubation after decannulation of the tracheostomy tube. Manual ventilation of both lungs, verification of tube placement by auscultation and capnography were performed. The position of the DLT was controlled and maintained using a fiber-optic bronchoscope. Separate ventilation of the left lung was maintained in BiPAP mode, while the right lumen of the tube was disconnected from the wall suction and water seal. A total of $4 \mathrm{~g}$ of talc (Steritalc F2, No-

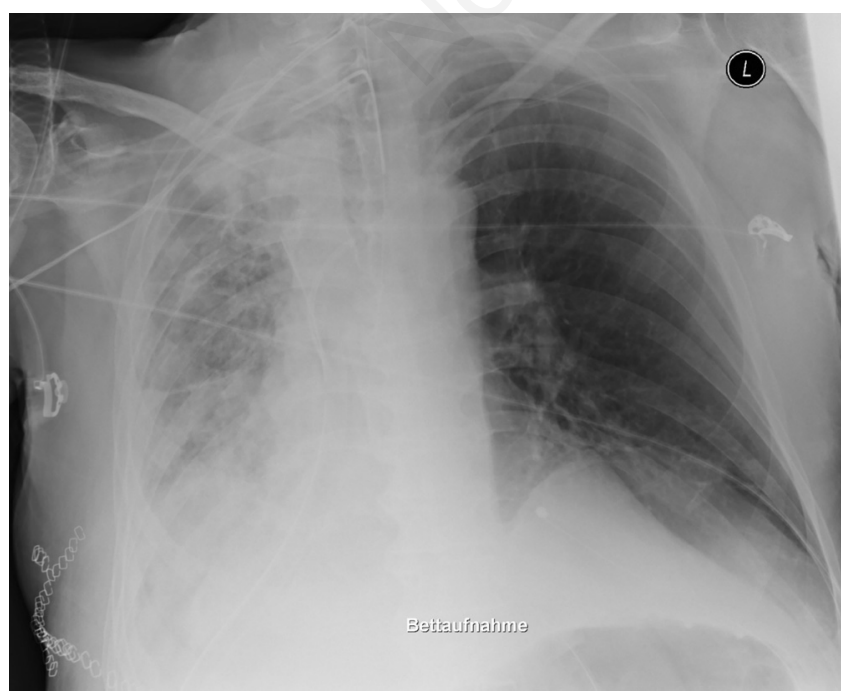

Figure 1. Chest radiograph after talc pleurodesis. vatech SA, La Ciotat, France) in $100 \mathrm{ml} \mathrm{G40 \%} \mathrm{solution} \mathrm{(Glucose} \mathrm{40 \% ,} \mathrm{B.}$ Braun, Melsungen, Germany) was administered via the chest tube into the right pleural cavity, and finally, the chest tube was clamped. The distribution of talc solution was achieved by positioning maneuvers (moving the torso up and down). During the procedure, the patient was ventilated through the left side of the DLT. After 17 minutes, the patient developed hypoxia; the SLV was discontinued and mechanical ventilation of both lungs was performed. The DLT was removed, and the tracheal tube was reinserted, followed by a quick fiber optic view, and BiPAP ventilation was continued. Finally, a chest radiograph was performed at bedside (Figure 1).

The right chest tube was disconnected and was removed 3 days later (Figure 2). This was followed by an uncomplicated adaptation to a volume-controlled CPAP mode, and the patient was transferred to the rehab unit for spinal cord injuries. The rehabilitation process lasted more than three months. The progress during the multimodal treatment was gratifying.

Initially, the patient suffered a pharyngeal dysphagia with a high risk for pulmonary aspiration and subsequent pneumonia. The diagnosis was confirmed by a fiber optic endoscopic evaluation of swallowing (FEES). A percutaneous endoscopy gastrostomy tube was used to provide sufficient nutritional support. With time, treatments focused on logopedics, such as swallowing therapy, with deflation of the cuff of the tracheostomy tube. Dysphagia therapy has been used to strengthen the muscles involved in swallowing, as well as to promote sensitivity. An important goal in the patient regaining autonomy was also achieved as he regained his voice and began to speak. Unfortunately, the FEES reevaluation showed persistent pharyngeal dysphagia with a risk for potential aspiration, even after twelve weeks of treatment.

The patient was weaned from the respirator during the day. At night, he was ventilated with a portable respirator in a volume-controlled mode, with a tidal volume of $700 \mathrm{ml}$, ventilation frequency of 18 per minute, inspiratory-to-expiratory ratio of 1:1.7 and PEEP of $0 \mathrm{cmH}_{2} 0$.

At the time of discharge from the rehab department, an examination revealed a further flaccid tetraplegia. The muscular reflexes were not able to be triggered and were only very weakly triggered on the right upper limb. Babinski reflexes were no longer present.

In the area of the right upper limb on all sides, the muscle strength was a grade of 4 (of 5).

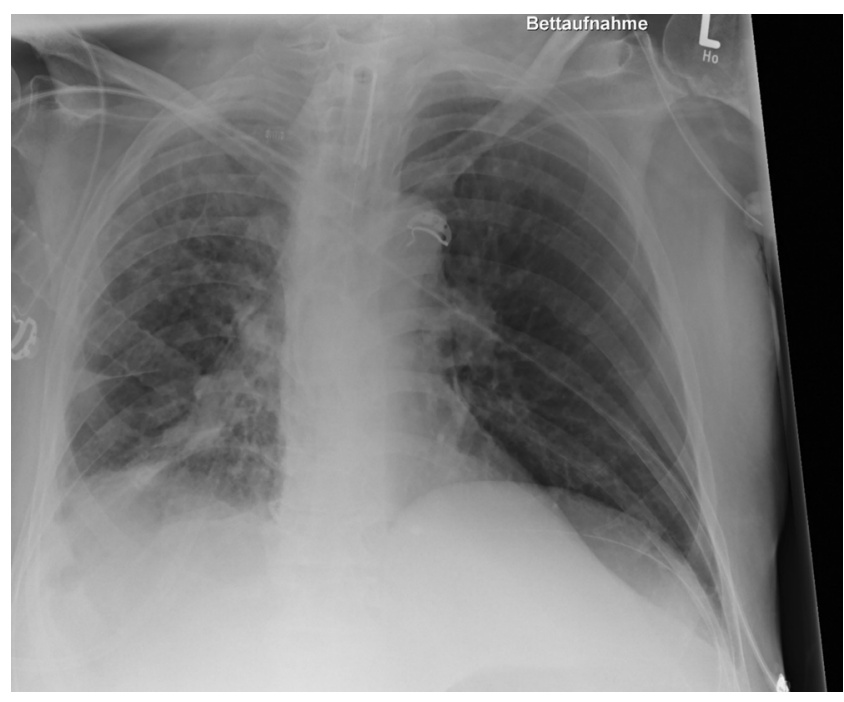

Figure 2. Chest radiograph after removal of the right chest tube. 
In the region of the left upper limb for all muscle groups, the muscle strength was a 1 (of 5). The fourth and fifth fingers on the left hand were easily moved.

In the region of the right lower extremity at the hip flexors and extensors, the muscle strength was a grade of 3 (of 5). In the area of the knee extensors and knee flexors, the muscle strength was a grade between 2 and 3 (of 5).

In the area of the left lower extremity on all sides, the muscle strength was a grade of 1 (of 5). Urinary bladder emptying was performed with intermittent catheterization.

\section{Discussion}

Broncho- or pleuroparenchymal fistula is associated with significant morbidity and mortality [2-5]. The treatment aim is to achieve the best possible result without additional harm. Sterile talc is the most often used effective chemical agent for pleurodesis, but its application can also lead to acute respiratory distress syndrome (ARDS) and respiratory failure [14-16]. Interestingly, our patient subsequently showed a stable respiratory condition even when the chest tube was disconnected and removed. The short-term separate left-sided lung ventilation led to the successful closure of the PPF. We conclude that the combination of temporary separate lung ventilation and talc pleurodesis is a promising approach to occlusion of the PPF in patients who are unable to undergo surgical treatment.

The progress of rehabilitation focused on the spinal cord injury, swallowing therapy and weaning from the ventilator, and demonstrates that rehabilitation can be achieved and that the patient can improve to a certain degree of autonomy and mobility.

\section{Conclusions}

The non-surgical management of a persistent PPF with temporary separate lung ventilation (SLV) via a double-lumen tube (DLT) in combination with talc pleurodesis is an feasible approach in patients who are unable to undergo surgical treatment.

\section{References}

1. Asamura H, Kondo H, Tsuchiya R. Management of the bronchial stump in pulmonary resections: a review of 533 consecutive recent bronchial closures. Eur J Cardio-Thorac 2000;17:106-10.
2. Cerfolio RJ. The incidence, etiology, and prevention of postresectional bronchopleural fistula. Seminars in Thoracic and Cardiovascular Surgery 2001;13:3-7.

3. Hollaus PH, Lax F, El-Nashef BB, et al. Natural history of bronchopleural fistula after pneumonectomy: a review of 96 cases. Ann Thorac Surg 1997;63:1391-6; Discussion 6-7.

4. Pierson DJ, Horton CA, Bates PW. Persistent bronchopleural air leak during mechanical ventilation. A review of 39 cases. Chest 1986;90:321-3.

5. Sirbu H, Busch T, Aleksic I, et al. Bronchopleural fistula in the surgery of non-small cell lung cancer: incidence, risk factors, and management. Ann Thorac Cardiovas 2001;7:330-6.

6. Boudaya MS, Smadhi H, Zribi H, et al. Conservative management of postoperative bronchopleural fistulas. J Thorac Cardiov Sur 2013;146:575-9.

7. Santini M, Vicidomini G, La Monica G, Pastore, V. Use of a modified endobronchial tube for mechanical ventilation of patients with bronchopleural fistula. Eur J Cardio-Thorac 2005;28:169-71.

8. Shin SY, Lee H, Kwon W, Ryu, HG. Management of bronchopleural fistula using a modified single lumen tube. Korean Journal of Anesthesiology 2013;65:S127-9.

9. Swol J, Buchwald D, Dudda M, et al. Veno-venous extracorporeal membrane oxygenation in obese surgical patients with hypercapnic lung failure. Acta Anaesth Scand 2014;58:534-8.

10. Garlick J, Maxson T, Imamura M, et al. Differential lung ventilation and venovenous extracorporeal membrane oxygenation for traumatic bronchopleural fistula. Ann Thorac Surg 2013;96:1859-60.

11. Daoud 0, Augustin P, Mordant P, et al. Extracorporeal membrane oxygenation in 5 patients with bronchial fistula with severe acute lung injury. Ann Thorac Surg 2011;92:327-30.

12. Khan NU, Al-Aloul M, Khasati N, et al. Extracorporeal membrane oxygenator as a bridge to successful surgical repair of bronchopleural fistula following bilateral sequential lung transplantation: a case report and review of literature. J Cardiothorac Surg 2007;2:28.

13. Korvenoja P, Pitkanen 0, Berg E, Berg, L. Veno-venous extracorporeal membrane oxygenation in surgery for bronchial repair. Ann Thorac Surg 2008;86:1348-9.

14. Sahn SA. Talc should be used for pleurodesis. Am J Resp Crit Care 2000;162:2023-4; Discussion 6.

15. Rehse DH, Aye RW, Florence MG. Respiratory failure following talc pleurodesis. Am J Surg 1999;177:437-40.

16. De Campos JR, Vargas FS, De Campos Werebe E, et al. Thoracoscopy talc poudrage: a 15-year experience. Chest 2001;119:801-6. 